\title{
THE DRILLING INVESTIGATION OF GLASS FIBRE REINFORCED PLASTIC
}

\author{
Richárd HORVÁTH ${ }^{1}$, Gábor ÁGOSTON² \\ 1,2 Óbuda University, Donát Bánki Faculty of Mechanical and Safety Engineering, Institute of Materials and \\ Manufacturing Sciences, Budapest, Hungary, horvath.richard@bgk.uni-obuda.hu
}

\begin{abstract}
Nowadays the usage of glass fibre-reinforced plastics (GFRP) is increasing. The cutting of these materials entails several problems, e.g. the strong abrasive wear effect of the glass fibres or delamination effects. In this paper, we examine the results of drilling experiments on a $10 \mathrm{~mm}$ thick GFRP which included 26 layers. The cutting parameters were changed over a wide range. During the experiments, we measured the average surface roughness parameter (Ra). After the tests, we examined the effect of the cutting parameters on the measured roughness values. We created two types of predictive model to estimate the roughness parameter and compared their applicability.
\end{abstract}

Keywords: GFRP, drilling, average surface roughness, response surface method.

\section{Introduction}

Glass fibre reinforced plastics are widely used thanks to their excellent properties of high strength, low weight and cost-effectiveness. These materials may be machined because of the required dimensional accuracy or geometric shape. The machining of GFRP materials entails many problems. Too high a temperature may melt the matrix material, but due to possible moisture absorption (in epoxy matrix composites), cooling-lubrication is not recommended. Also, delamination and burr during cutting have to be minimized.

Okutan et al. [1] investigated the drilling of GFRP in dry conditions and at constant cutting speed. Four drill bits of different diameters were used and feed was varied at four levels too. They examined the drilled surfaces with an electron microscope and created exponential models to estimate axial force and torque.

Vankanti and Ganta [2] calculated the optimal cutting parameters of drilling GFRP. The optimized parameters were cutting speed, feed, and the geometry of the tool volt. They examined the effect of cutting parameters and tool geometry on the axial force, torque, the surface roughness of the cut, and circularity.
Kumar and Sing compared a high-speed steel drill and two types of carbide drills [3]. Their input parameters were the three drill bits, and they varied cutting parameters at three levels, too. They used their results to create empirical models for delamination factor, the surface roughness parameters and axial force. They found that delamination increased due to the effect of feed direction force. Surface roughness increases as cutting speed increases.

Parida et al. [4] used the response surface method for the drilling of GFRP. They used three different high-speed steel drills and varied cutting speed and feed at three levels. They made a second-order response surface model and determined optimal cutting parameters. They found that cutting speed has the greatest effect on surface roughness; drill bit diameter has a smaller effect, while the effect of feed is negligible.

Khashaba and El-Keran [5] published a comprehensive study on the drilling of GFRP. They varied cutting speed at three levels and feed at two levels. They measured temperature, feed force, surface roughness and investigated delamination.

Velaga and Cadambi [6] investigated the effect of cutting parameters when drilling GFRP materials. They used high-speed steel drill bits and 
three different cutting speeds and feeds. They examined delamination, performed finite element model tests and determined optimal cutting parameters to minimize delamination.

Mohan et al. [7] investigated the drilling of GFRP materials with the Taguchi method. They varied input parameters (the thickness of the GFRP material, drill bit diameter and cutting parameters) at four levels. They investigated delamination in detail and the effect of cutting parameters on delamination phenomena.

In this article, we present the results of the drilling investigation of $10 \mathrm{~mm}$ thick glass fibre reinforced plastic. The surface roughness parameter $(R a)$ of the drilled surfaces is examined as a function of cutting parameters.

\section{Materials and methods}

In the GFRP used in the tests, the glass fibres were placed in 26 layers, perpendicular to each other (Figure 1.).

In the case of glass fibre reinforced materials, tool wear is more pronounced, therefore diamond or diamond coated tools are recommended. Thus, we used a $\emptyset 10 \mathrm{~mm}$ diamond coated drill bit of the DreamDrills product family [8]. The tests were performed on a MAZAK VCN 410A-II machine tool, and surface roughness was measured with a Mitutoyo SJ-301 roughness tester.
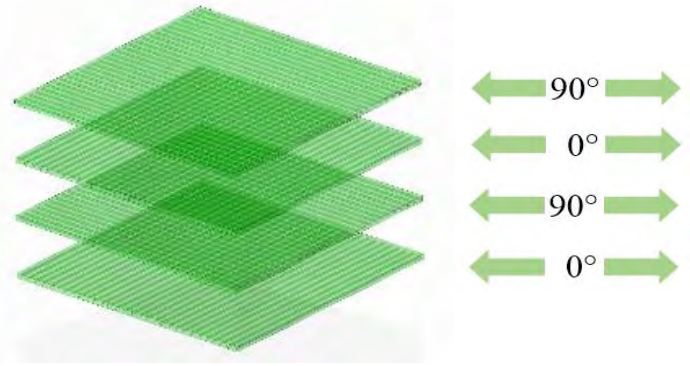

Figure 1. The fibre order of the glass fibres in the workpiece

\subsection{Predictive models}

It is beneficial to create phenomenological models with which the examined parameters of the cut surface (in our case average surface roughness) can be estimated with acceptable accuracy in the examined cutting parameter range. There are basically two approaches. One is the so-called second-order response surface model [1, 4] (1), which contains the cutting parameters, their squared effect and their cross effect (model I):

$$
\begin{aligned}
Y=b_{0} & +b_{1} \cdot v_{c}+b_{2} \cdot f_{z}+b_{11} \cdot v_{c}^{2} \\
& +b_{22} \cdot f_{z}^{2}+b_{12} \cdot v_{c} \cdot f_{z}
\end{aligned}
$$

The other is the so-called exponential model [3] (model II), whose formula is the following (2):

$$
Y=c_{0} \cdot v_{c}{ }^{c_{1}} \cdot f_{z}^{c_{2}}
$$

where

$Y$ is the output parameter,

$b_{0}, b_{i} \ldots b_{i j}, c_{0}, c_{i} \ldots c_{i j}$ are calculated coefficients, $v_{c} f_{z}$ are the input (cutting) parameters.

We used the above two models to determine the predictive models of surface roughness and their investigation.

\subsection{The definition of experimental runs}

Based on the literature, we set out to examine a cutting parameter range as wide as possible. Cutting speed was $v_{c}=10-20-30-40 \mathrm{~m} / \mathrm{min}$, while feed rate was $f_{z}=0,02-0,04-0,06-0,08 \mathrm{~mm}$. Cutting tests were performed with each parameter combination.

\section{Results}

\subsection{The effect of cutting parameters on sur- face roughness}

Figure 2. shows $R a$ as a function of cutting parameters. $R a$ increases as cutting speed increases, while feed does not have such a strong effect.

\subsection{Predictive models}

Based on (1) and (2), we made predictive models for the $R a$ surface roughness parameters of the holes. The second-order response surface model is:

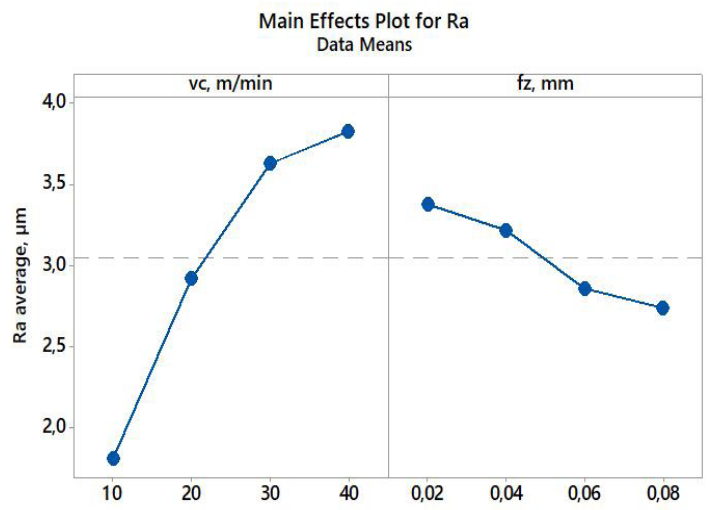

Figure 2. The main plots of $R a$ 


$$
\begin{gathered}
R_{a}=0,184+0,1971 \cdot v_{c}-5,5 \cdot f_{z}-0,001703 \cdot v_{c}{ }^{2} \\
+164 \cdot f_{z}^{2}-0,759 \cdot v_{c} \cdot f_{z}
\end{gathered}
$$

The exponential model is:

$R_{a}=0,3383 \cdot v_{c}{ }^{0,562} \cdot f_{z}^{-0,1385}$

Figure 3. shows the effect of cutting parameters on the Ra parameter based on Equation (3).

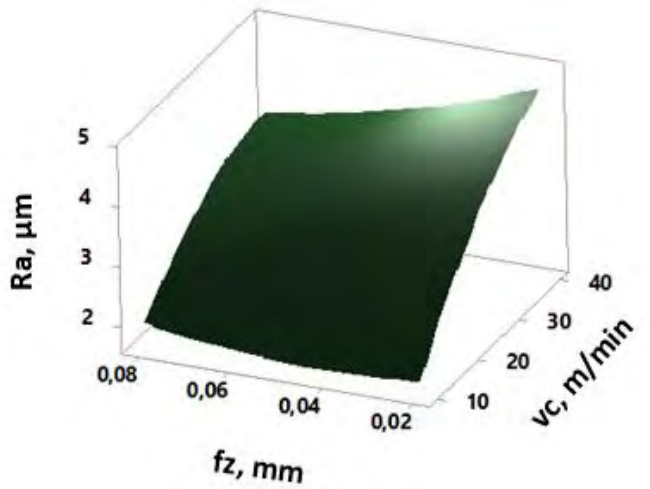

Figure 3. The graphical representation of equation (3)

a)

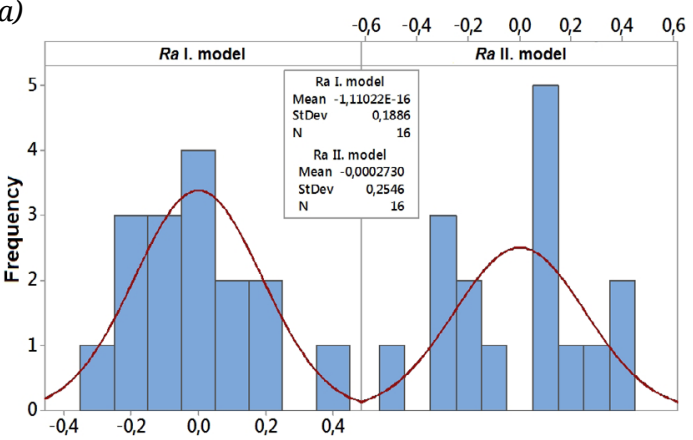

b)

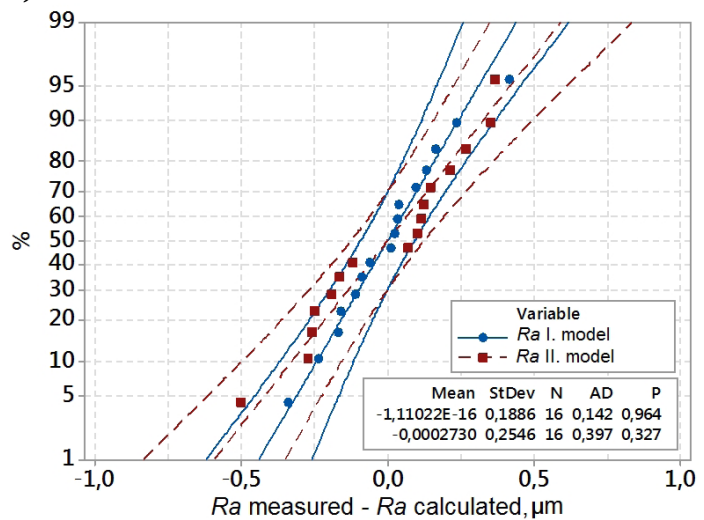

Figure 4. The investigation of residuals

a) Histogram of residuals

b) Representing residuals on probability plots

\subsection{The investigation and verification of the models}

Predictive models are appropriate if the difference between measured and calculated values (residuals) is as small as possible, their average is around zero, and their standard deviation is as low as possible. Figure 4. shows the residuals of Ra values with a histogram on a probability plot. The two figures show that the distribution of the residuals of the model $\mathrm{I}$ is nearer the expected normal distribution. The differences are between $-0.337 \mu \mathrm{m}$ and $0.41 \mu \mathrm{m}$, and their standard deviation is $0.1886 \mu \mathrm{m}$. On the other hand, the similar parameters of model II show bigger differences and standard deviation. The difference of the errors is between $-0.5 \mu \mathrm{m}$ and $0.36 \mu \mathrm{m}$, and their standard deviation is $0.2546 \mu \mathrm{m}$.

\section{Conclusions}

In this project, we performed the drilling investigation of a $10 \mathrm{~mm}$ thick, 26 layer GFRP material. After the drilling tests, we measured average surface roughness. We created two predictive models to estimate surface roughness. The tests produced the following results:

- Cutting speed has a great effect on average surface roughness $(\mathrm{Ra})$, while feed only has little effect on it;

- Although both models estimate Ra with the following accuracy for preliminary technological planning, the model I is more accurate, the distribution of errors approximates normal distribution better and the standard deviation is lower.

\section{Acknowledgements}

„Supported by the ÚNKP-17-4-I-OE-779/60 New National Excellence Program of the Ministry of Human Capacities."

We wish to express our thanks to GranTOOL Kft. for providing the tools for the experiments, and KANDSI Kft. (AKOBEZ), for providing the tailor-made workpieces.

\section{References}

[1] Okutan E., Karabay S., Sinmazçelik T., Avcu E. : A Study on Derivation of Parametric Cutting Force Equations In Drilling of GFRP Composites. Strojniški vestnik-Journal of Mechanical Engineering, 59/2. (2013) 97-105.

https://doi.org/10.5545/sv-jme.2012.774

[2] Vankanti V. K., Ganta V.: Optimization of process parameters in the drilling of GFRP composite 
using Taguchi method. Journal of Materials Research and Technology, 3/1. (2014) 35-41. https://doi.org/10.1016/j.jmrt.2013.10.007

[3] Kumar D., Sing K. K.: Experimental analysis of Delamination, Thrust Force and Surface roughness on Drilling of Glass Fibre Reinforced Polymer Composites Material Using Different Drills. Materials Today: Proceedings, 4/8. (2017) 7618-7627. https://doi.org/10.1016/j.matpr.2017.07.095

[4] Parida A. K., Routara B. C., Bhuyan R. K.: Surface roughness model and parametric optimization in machining of GFRP composite: Taguchi and Response surface methodology approach. Materials Today: Proceedings 2/4-5. (2015) 3065-3074. https://doi.org/10.1016/j.matpr.2015.07.247

[5] Khashaba U. A., El-Keran A. A.: Drilling analysis of thin woven glass-fibre reinforced epoxy compos- ites. Journal of Materials Processing Technology 249. (2017) 415-425. https://doi.org/10.1016/j.jmatprotec.2017.06.011

[6] Velaga M., Cadambi R. M.: Drilling of GFRP Composites for Minimising Delamination Effect. Materials Today. Proceedings, 4/10. (2017) 1122911236.

https://doi.org/10.1016/j.matpr.2017.09.044

[7] Mohan N. S., Kulkarni S. M., Ramachandra A.: Delamination analysis in drilling process of glass fiber reinforced plastic (GFRP) composite materials. Journal of Materials Processing Technology, 186/1-3. (2007) 265-271.

https://doi.org/10.1016/j.jmatprotec.2006.12.043

[8] GranTOOL: Carbide, Dream Drills - CFRP (accessed: January 2018)

http://www.toolontool.hu/DNNGranTool/PDF/ YG-1_Drill_DI473.pdf 